\title{
PENERAPAN MOTION TWEEN UNTUK ANIMASI DUA DIMENSI RUTE PERJALANAN BUS TRANS JOGJA
}

\author{
Dwi Nugraheny, Anton Setiawan Honggowibowo, Mega Lesya Mukti \\ Jurusan Teknik Informatika STTA \\ Jl. Janti Blok R Lanud Adisutjipto I
}

\begin{abstract}
Transportation is one of the important aspects in a region, where public transportation take effect on the mobility of the people. To achieve a good transportation can be create, so that the infrastructure and other supporting factors are needed. Yogyakarta municipality area has a lot of public transportasion, one of them is "Trans Jogja" bus, where each bus line has its route to reach any destination. It is needed a supporting media that can provide information about the route for each bus line so that people can be easily deciding which bus line that can use to reach their destination. Those information presented in the form of animation with an interesting and informative media. The use of animation as an information media that shown as a route trip, bus line including bus stop and departing passangers place assessed can be use as one of the other option for obtaining information except from a conventional map.
\end{abstract}

Keywords: Motion Tween, Two Dimensional Animation, Trans Jogja Bus Route.

\section{PENDAHULUAN}

Banyak faktor yang mendukung berkem-bangnya suatu wilayah. Satu diantaranya adalah kemudahan dalam bermobilitas, karena setiap harinya akan ada banyak orang yang melakukan kegiatan ke berbagai tempat, sehingga untuk mengakses tempat-tempat tujuan tersebut diperlukan suatu alat transportasi yang mudah untuk digunakan. Baik itu alat transportasi umum atau alat transportasi pribadi (Boru, 2008).Di Yogyakarta, pengguna alat trans-portasi umum tidaklah sedikit, maka dari itu alat transportasi umum tidak boleh dipandang sebelah mata, mulai dari beberapa tahun yang lalu, Yogyakarta telah memiliki alat transportasi umum Trans Jogja yang memiliki beberapa pilihan rute perjalanan dan halte atau shelter tempat pemberhentian serta pemberangkatan di beberapa macam tempat. Alat transportasi ini dapat dijadikan satu diantara banyak pilihan jenis transportasi untuk melakukan mobilitas ke berbagai tempat di wilayah kodya Yogyakarta.

Walaupun telah disediakan peta rute jalur Trans Jogja dan operator pada tiap halte yang siap menjawab pertanyaan mengenai jalur bus Trans 
Jogja, namun masih banyak pengguna ataupun calon pengguna bus Trans Jogja yang merasa bingung mengenai informasi jalur rute Trans Jogja yang dapat digunakan untuk mencapai ke tempat tujuan. Untuk mengatasi kendala tersebut, maka perlu dibuat suatu media untuk menginformasikan kepada pengguna maupun calon pengguna mengenai jalur bus Trans Jogja yang dapat digunakan untuk mencapai tempat yang akan dituju. Media tersebut dapat berupa suatu animasi, dimana penyampaianya dibuat informatif dan menarik sehingga pengguna bus Trans Jogja dapat dengan mudah memahami informasi pilihan jalur bus yang dapat digunakan untuk sampai ke tempat tujuan. Hal tersebut juga dapat menjadi nilai tambah tersendiri bagi perkembangan transportasi di wilayah kodya Yogyakarta.

\section{METODE PENELITIAN}

\section{A. Kebutuhan Perangkat Keras}

Perangkat keras yang digunakan dalam perancangan dan pembuatan animasi ini adalah sebagai berikut :

1. Processor : Intel(R) Core(TM) i3 CPU M380@2.53Ghz (4 CPUs), $2.5 \mathrm{GHz}$

2. RAM : DDR3 4096MB.
3. VGA : AMD Radeon HD 640M.

4. Harddisk $500 \mathrm{~GB}$

5. Layar 14"

\section{B. Kebutuhan Perangkat Lunak}

Perangkat lunak yang digunakan dalam perancangan sistem adalah sebagai berikut :

1. Sistem Operasi Windows 7

2. AdobeFlash CS4

3. Adobe DreamweaverCS4

4. Bahasa pemrograman XML

5. AdobeIllustrator

C. Diagram Konteks

Diagram konteks aplikasi animasirute Bus Trans Yogya yang dibuat dapat dilihat pada Gambar 1.

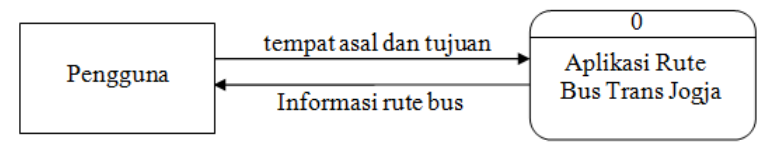

Gambar 1. Diagram Konteks

Aplikasi Rute Bus Trans Jogja

\section{DAD Level 1}

DAD level 1 seperti yang ditampilkan pada Gambar 2 menjelaskan bahwa pengguna dapat mencari rute perjalanan yang dapat ditempuh dengan menginputkan tempat asal dan tempat tujuan, kemudian berdasarkan inputan tersebut akan dilakukan proses pencocokan data yang sesuai yang kemudian hasilnya akan ditampilkan dalam bentuk animasi. 


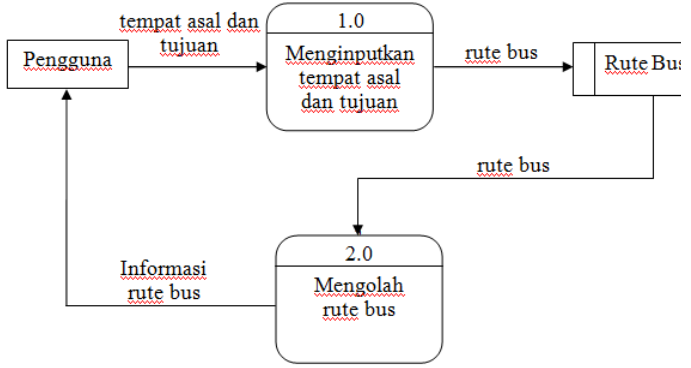

Gambar 2. DAD Level 1 Aplikasi Rute BusTrans Jogja

\section{E. Diagram Alir (Flowchart) sistem}

Adapun rangkaian langkah-langkah pembuatan animasi rute bus trans yogya dari awal penggunaan program yaitu mengawalinya dengan mulai menginput tempat asal dan tempat yang akan menjadi tujuan. Jika tempat asal dan tujuan sesuai dengan data yang telah tersimpan sebelumnya, maka akan ditampilkan rute perjalanan dan jalur bus yang sesuai yang dapat digunakan untuk mencapai tempat tujuan. Penggambaran flowchart dari aplikasi rute perjalanan Trans Jogja dapat dilihat pada Gambar 3.

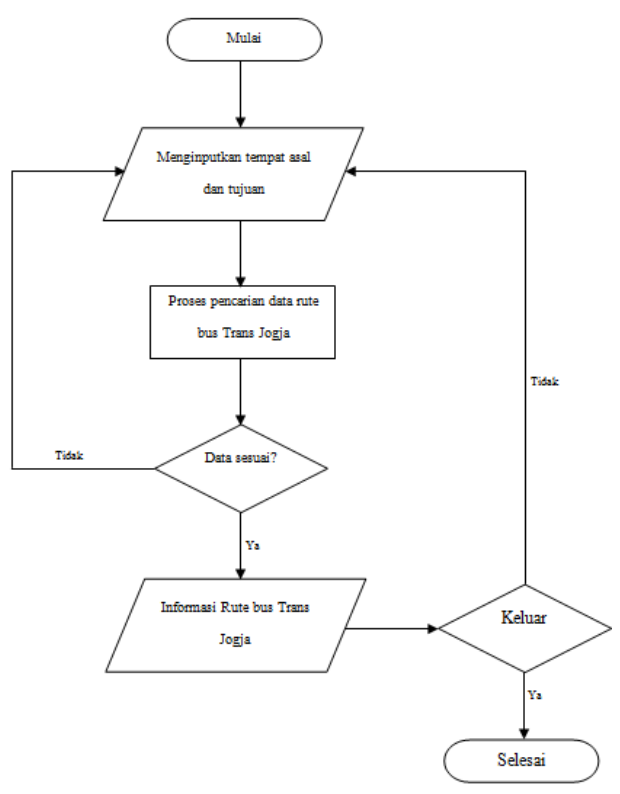

\section{Gambar 3. Diagram Alir Aplikasi Rute BusTrans Jogja}

\section{F. Perancangan data XML}

Pada aplikasi ini, semua data mengenai tempat asal, tempat tujuan serta trayek yang dapat digunakan akan disimpan. Dimana nantinya aplikasi akan melakukan pencocokan data dari tempat asal dan tempat tujuan dengan trayek yang sesuai dengan data yang sudah ada. Berikut adalah struktur dari dokumen XML yang digunakan :

$<$ data $>$

$$
\begin{aligned}
\text { <jalur }> & \\
& <\mathrm{id}></ \text { id }> \\
& <\text { asal }></ \text { asal }> \\
& <\text { tujuan }></ \text { tujuan }> \\
& <\text { animasi }></ \text { animasi }>
\end{aligned}
$$

$<$ keterangan $></$ keterangan $>$

$<$ jalur $>$ 
$</$ data $>$

\section{IMPLEMENTASI DAN ANALISA}

\section{HASIL}

\section{A. Penjelasan Hasil Rancangan}

Aplikasi rute perjalanan bus Trans Jogja ini merupakan aplikasi yang mengintegrasikan pemrograman Flash dengan bahasa XML. Pemrograman dengan Flash membentuk antarmuka sedangkan bahasa XML berfungsi untuk menampung data yang digunakan aplikasi. Antarmuka Flash berisikan perintah untuk memproses data pada dokumen XML. Data yang sudah dimasukkan oleh user akan dikirim dan dicocokkan dengan data yang ada pada dokumen XML. Kemudian output yang diperoleh akan diterima aplikasi dan ditampilkan pada antarmuka Flash (Baba, 2003). Proses yang terjadi merupakan perintah yang sudah dimasukkan dalam actionscript yang terdapat pada Flash. Aplikasi rute perjalanan bus Trans Jogja ini juga dapat dibuat sebagai aplikasi client-server dengan memanfaatkan jaringan internet. Dokumen XML dan dokumen movie eksternal dapat diunggah pada suatu domain. Kemudian aplikasi akan memberikan perintah untuk mengakses dokumen tersebut. Kemudian mengolahnya untuk selanjutnya movie eksternal yang cocok ditampilkan pada aplikasi yang sudah disimpan pada perangkat komputer. Hal ini dapat dimungkinkan jika koneksi internet berkualitas bagus, dikarenakan aplikasi akan memuat movie yang berukuran tidaklah kecil.

\section{B. Uji Fungsi}

Aplikasi rute perjalanan bus Trans Jogja membutuhkan pengujian sebagai suatu prosedur yang dilakukan untuk mengetahui apakah tersebut siap untuk dijalankan sesuai dengan yang apa yang telah dirancang sebelumnya. Dimana pada tahap ini akan dibahas mengenai desain input data, desain proses data dan desain output sistem yang berupa gambar animasi perjalanan bus Trans Jogja. Melalui pengujian ini maka akan dapat diketahui bahwa sistem yang dijalankan sudah berjalan dengan sesuai atau tidak.

$$
\text { Pada menu utama terdapat }
$$

beberapa button yang memiliki fungsinya masing-masing. Button tersebut adalah button Cari Rute, Help, About dan Exit. Button Cari Rute berfungsi untuk mencari rute perjalanan dengan bus Trans Jogja, button Help berfungsi untuk menjelaskan mengenai cara pemakaian dan fungsi aplikasi, button About berfungsi untuk menuju ke halaman yang menerangkan tentang pembuatan aplikasi, dan button Exit berfungsi untuk menutup dan 
mengakhiri jalannya program. Untuk menu content dapat dilihat pada Gambar 4.

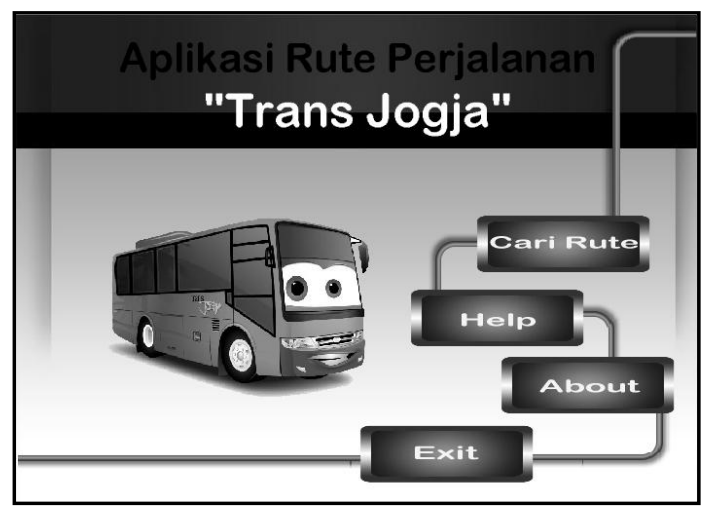

Gambar 4. Menu Content

Pada pilihan Cari Rute terdapat forminput yang merupakan form untuk pencarian rute, tampilannya berupa dua buah inputtext dan satu button untuk mengirimkan data yang sudah dimasukkan ke dalam masing-masing inputtext. Dimana inputtext tersebut masing-masing adalah input text untuk memasukkan data tempat asal dan tempat tujuan. Tampilan forminput, dapat dilihat pada Gambar 5.

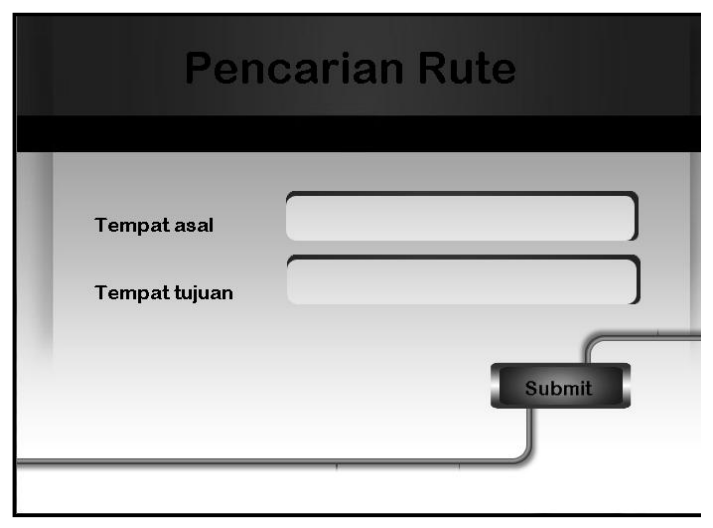

Gambar 5. Forminput Cari Rute
Jika terdapat data yang sesuai dengan inputan yang dimasukkan, maka aplikasi akan menampilkan movie animasi pada antarmuka Flash. Movie tersebut memiliki pilihan button play untuk memutar animasi trayek bus Trans Jogja. Selain itu terdapat button back, keluar dan keterangan. button back berfungsi untuk kembali ke form inputan cari rute seperti yang ditampilkan pada Gambar 5, sedangkan button keluar digunakan untuk menutup serta mengakhiri jalannya program dan button keterangan berfungsi untuk menampilkan keterangan mengenai rute perjalanan, bus yang digunakan dan halte tempat naik, turun serta transit yang digunakan. Pada movie animasi, halte tersebut ditampilkan dengan logo bus berwarna hijau. Jika bus melewati logo tersebut maka bus melewati halte yang dimaksudkan. Tampilan untuk antarmuka ini dapat dilihat pada Gambar 6.

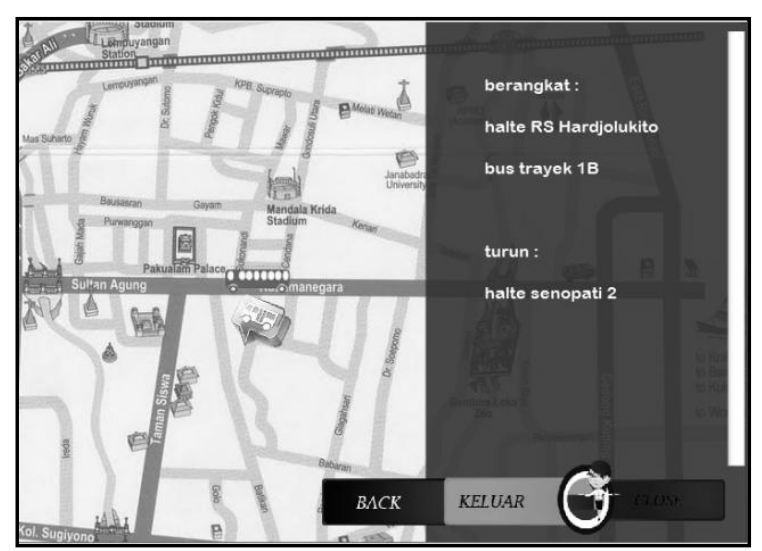

Gambar 6. Tampilan movie animasi 


\section{Analisa Hasil}

Aplikasi rute perjalanan bus

Trans Jogja menerapkan konsep motion tween dalam pembuatan animasinya. Dengan konsep ini, objek bus diletakkan pada frame awal dimana halte pemberangkatan berada, kemudian dipindah pada frame-frame berikutnya sampai pada frame terakhir tempat halte tujuan. Dari hasil input yang dilakukan user, kemudian dilakukan pencocokan data pada dokumen XML, outputmovie animasi yang dihasilkan adalah hasil pergerakan motion tween dari objek yang terdapat pada frame-frame sesuai dengan timing yang sudah diatur. Hasil input tempat asal yang dilakukan user, objek bus pada movie animasi diletakkan pada objek halte terdekat di daerah tempat asal seperti yang dapat dilihat pada Gambar 7.

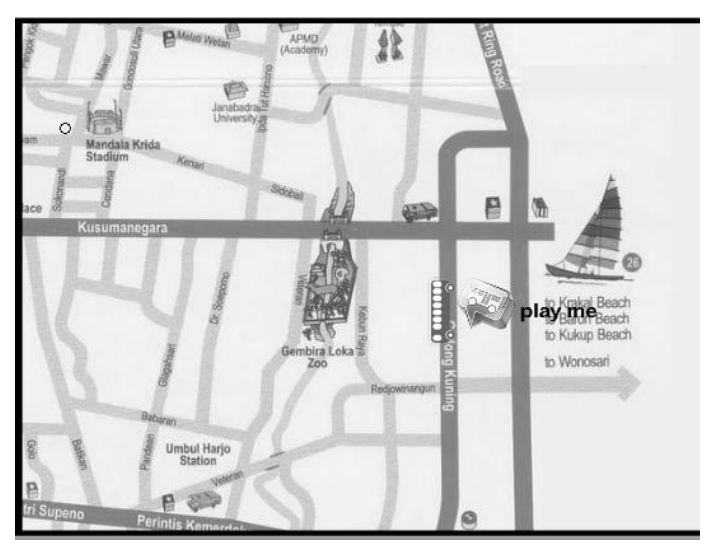

Gambar 7.Frame pertama

Pada timeline, frame pertama dijadikan sebagai keyframe untuk frame- frame berikutnya. Pada timeline seperti yang dapat dilihat pada Gambar 8, keyframe diletakkan pada frame 35 dan posisi objek bus diubah sesuai rute trayek bus Trans Jogja.

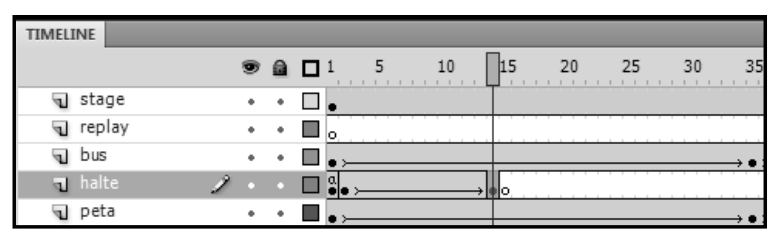

\section{Gambar 8.Timeline frame rute animasi}

Pada frame 35 dimana keyframe disisipkan, objek bus diposisikan pada peta sesuai dengan rute yang dilalui bus Trans Jogja seperti yang dapat dilihat pada Gambar 9.

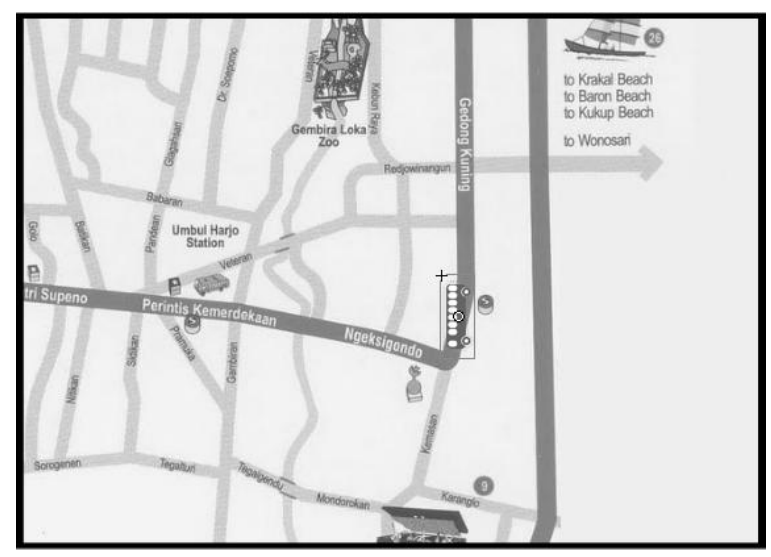

\section{Gambar 9. Posisi objek bus pada frame 35}

\section{Diantara frame 1 dan frame 35} terdapat frame-frame kosong, karena frame 35 berbentuk keyframe, maka frame kosong tersebut akan mengikuti tampilan yang ada pada frame sebelumnya. Objek bus yang telah dipindahkan posisinya maka tampilanya 
akan berubah, agar pergerakan objek bus teratur maka pada frame kosong tersebut akan dibuat classic tween. Dengan demikian, objek bus akan terlihat bergerak sesuai dengan posisi awal pada frame pertama sampai pada frame 35 .

Aplikasi ini dibuat agar memudahkan pengguna dalam bermobilisasi menggunakan transportasi umum meskipun belum mengetahui rute mana yang akan dilalui untuk mencapai tempat tujuan serta bus mana yang dapat digunakan untuk menempuh perjalanan. Jika dibandingkan dengan menggunakan peta, seluruh rute tercampur menjadi satu. Walaupun sudah dibuat dalam berbeda-beda warna namun masih cukup sulit dalam menentukan rute jalan yang akan ditempuh, karena untuk mencapai tempat tujuan tidak jarang harus melalui proses transit terlebih dahulu untuk berpindah jalur dengan menggunakan rute trayek bus dengan warna lain. Berbeda dengan peta konvensional, aplikasi rute perjalanan bus Trans Jogja, rute yang ditampilkan hanya satu, yaitu rute yang akan ditempuh dari tempat asal sampai tempat tujuan. Dimana jika terjadi transit, akan diberikan peringatan. Selain itu terdapat keterangan yang berisikan keterangan mengenai halte tempat pemberangkatan dan halte tempat tujuan terdekat, bus yang dipakai, dan keterangan mengenai transit jika memang untuk mencapai tempat tujuan tidak dapat langsung menggunakan satu trayek dan harus berpindah rute menggunakan bus dengan nomor trayek lain. Pada peta tidak dicantumkan penumpang naik melalui halte yang mana dan turun di halte yang mana, dengan peta pun penumpang harus bertanya kepada petugas untuk mengecek apakah trayek yang mereka akan gunakan melewati halte tersebut atau tidak.

pertanyaan yaitu 4 kemudian hasilnya dikalikan $100 \%$.

Pada Gambar 10 diperlihatkan mengenai diagram hasil presentase dari data kuesioner yang sudah diambil.

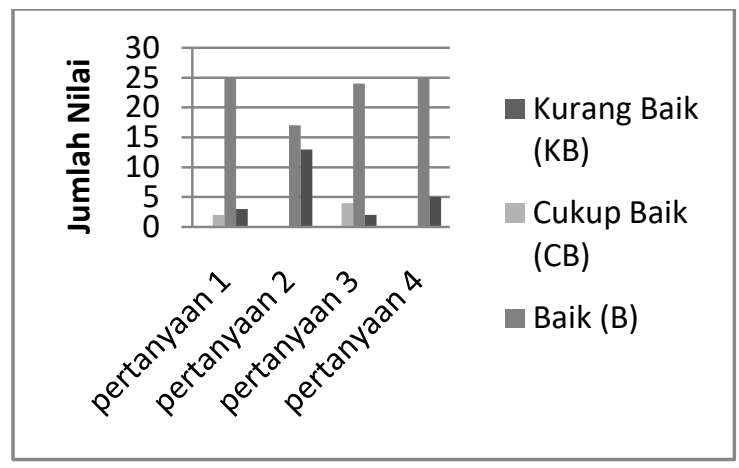

\section{Gambar 10. Diagram Hasil Presentase Kuesioner}

\section{KESIMPULAN}

1. Aplikasi dengan animasi rute perjalanan bus Trans Jogja dapat diselesaikan dengan menggunakan Adobe Flash dan XML.

2. Aplikasi rute perjalanan bus Trans Jogja dapat digunakan sebagai 
salah satu pilihan untuk memperoleh informasi rute bus selain menggunakan peta konvensional.

3. Berdasarkan survey kepada 30 koresponden, diperoleh hasil bahwa 75.83\% aplikasi dinilai baik, $19.17 \%$ menyatakan aplikasi sangat baik dan $5 \%$ sisanya menyatakan aplikasi cukup baik.

\section{SARAN}

1. Aplikasi rute perjalanan bus Trans Jogja dapat dikembangkan sebagai aplikasi berbasis website, agar setiap orang dapat dengan mudah mengakses dari website tersebut.

2. Aplikasi dapat dilengkapi dengan adanya keterangan mengenai halte bayangan, yang dimaksud dengan halte bayangan disini adalah halte yang hanya dapat digunakan sebagai tempat untuk turun penumpang.

\section{DAFTAR PUSTAKA}

Baba., 2003. Animasi Kartun dengan Flash MX. PT. Elex Media Komputindo. Jakarta.

Boru, M., 2008. Penggunaan Simulasi untuk Pemecahan Masalah Transportasi. Jurnal Komputer dan Sistem Intelijen (KOMM1T) Agustus 2008 ISSN : 14116286.

HM, Jogiyanto., 2005. Analisis dan Desain Sistem Informasi: Pendekatan Teori dan Praktek Aplikasi Bisnis. CV. Andi Offset. Yogyakarta.

Muslim, MA., 2005. Aplikasi Penentuan Rute Terbaik Berbasis Sistem Informasi Geografis. Jurnal Ilmiah Teknologi Informasi Dinamik No 2 Vol. 10 Mei 2005 : 76-83 ISSN : 08549524.

Simpson, J.E., 2002. Just XML. Penerbit Andi Offset. Yogyakarta.

Susilo,C.B dan Indrayana, D., 2012. Redesain Peta Digital Interaktif "Surabaya Map" Suara Surabaya Media dengan Konsep Active and Simplified.Jurnal Sains dan Seni ITS Vol. 1 September 2012 ISSN : 2301 928X. 